\title{
GONOCOCCAL INFECTION OF THE PARA-URETHRAL GLANDS IN THE FEMALE*
}

\author{
BY \\ ELISABETH REES \\ Liverpool Royal Infirmary
}

The introduction of the sulphonamide group of drugs, and later of penicillin, in the treatment of gonorrhoea resulted in a new concept of the treatment of this disease. Formerly, there had been an almost complete dependence upon methods of treatment applied locally to the site of the infection. But the effectiveness of these drugs, administered systemically, led to a concentration on new and better schemes for administering them, and local treatment was neglected.

During this period of evolution in the treatment of gonorrhoea many improvements were made in the technique of culturing the gonococcus. This has proved to be of great value in the diagnosis of gonorrhoea in the female. In those centres where good bacteriological facilities are available, approximately 60 per cent. of the bacteriologically positive diagnoses are made on the evidence of culture alone, microscopical examination of stained smears giving negative results. This has shown that gonococcal infection in a large proportion of women is asymptomatic. Nicol (1948), in a detailed analysis of 229 cases of gonorrhoea in women who attended the Whitechapel Clinic, found that 106 were symptomless and that 140 of the 229 attended only at the request of their male consorts.

In a case of uncomplicated gonorrhoea, cure is effected by any method of penicillin treatment which maintains a penicillin blood level of 0.03 units per ml. for a minimum of 6 hours (Moore, 1949). It is recognized, however, that when the gonococcus lies in a closed or intermittently draining focus it may escape the action of penicillin, and that it is thus a potential source of re-infection if the focus is re-opened. The recognition of the existence of such a focus is therefore essential to the ultimate success of the treatment.

The reported results of treatment by penicillin in the female are variable, and depend to a great extent upon the duration of post-treatment observation and the facilities available for cultural examination. In clinics where the period of

\footnotetext{
* Received for publication June 6, 1952.
}

observation is relatively long and the culture facilities are good, the number of successful treatments claimed tends to be less than where the opposite conditions prevail. In the United States of America cure is claimed to be so nearly certain that the follow-up of patients has been abandoned in many large clinics (Moore, 1949). This attitude is not supported in Great Britain where the importance of post-treatment observation in women is stressed, and where recently it has been suggested that although the results of penicillin treatment are extremely good there is a higher failure rate than was thought in the early days of its use (King and others, 1950).

The anatomical difficulties of examining the lesions of gonorrhoea in the female and the reluctance of the patients to submit to such examination has always made the treatment of this disease unsatisfactory. Consequently, these patients have not always received the attention which their condition demanded. Before the advent of chemotherapy and the antibiotics, gonorrhoea was responsible for much ill-health in women and had wider social implications in the resulting sterility and sub-fertility.

The prognosis in women has been completely altered since the introduction first of the sulphonamides and later of penicillin, but Mascall (1946) urged that this should not result in a too complacent attitude. He said :

In recent years the introduction of new and effective remedies has deterred from an interest which was never strong, for there is a tendency to assume that these infections are easily cured, and are not accompanied by serious after-effects. There is still no genuine recognition of the fact that this is a most damaging complaint with far-reaching consequences unless treated skilfully in the early stages.

King and others (1950), reporting on a series of cases treated with an adequate dosage of penicillin, suggest that some successes may be more apparent than real. In a series of 481 women treated, fifteen ( 3.5 per cent.) were regarded as immediate failures because the gonococcus persisted in the 15 
secretions, or reappeared within 2 weeks, and 56 (13.4 per cent.) showed the gonococcus in the secretions during observation 2 weeks or more after treatment. These authors conclude that penicillin is less effective in the treatment of acute uncomplicated gonorrhoea than it is reported to be. They do not, however, support the hypothesis that the reappearance of gonococci is due to their persistence in foci to which the penicillin in the blood stream does not penetrate. They state :

There is little or no evidence, for or against, this explanation for the patients seldom show clinical evidence of abscess formation or any other complication.

It has been suggested by Marshall (1945) that the theory of staphylococcal resistance propounded by Bigger (1944) may be applicable to the gonococcus, but there has been no evidence in support of this.

The alternative explanation is that certain strains of gonococci may be penicillin-resistant. Such resistance has not been demonstrated, although tests in vitro have been carried out on sub-cultures of gonococci which resisted treatment in vivo (Warner, 1944 ; Lees, 1946).

The resistance to treatment of gonococcal infection of the para-urethral, or Skene's, glands and ducts has been recognized since they were first described by Astruc (1761-65). The signs of acute infection of the ducts have been widely described, but during recent years the importance of signs of chronic infection which, as has been seen, are the commonest signs of gonococcal infection in the female are stressed only by Ross (1949) and Durel (1950a). The occurrence of gonococcal para-urethritis in the female, as recorded since the introduction of penicillin in the treatment of gonorrhoea, is very rare. Nicol (1948) reported one case in a series of 229. The majority of reports bear no reference to the occurrence of this complication.

Theoretically, from the anatomy and histology of the female urethra, infection of the para-urethral ducts would appear inevitable in a gonococcal infection of the urethra. In this belief, the writer has made and recorded a detailed examination of the urethra with particular reference to the ducts in 92 out of 106 consecutive female patients with gonorrhoea attending the Liverpool Royal Infirmary between February, 1948, and June, 1950. It was found that signs of chronic infection of the ducts are frequently present in association with positive cultural tests and smears negative for pus and gonococci.

The results suggest that gonococcal infection of the para-urethral ducts in the female is common, and that relapse is frequently due to the persistence of the infection in this site, and confirm the importance of culture examination in the female.

\section{Pathological Considerations}

Harkness (1948) states that the female urethra often escapes infection owing to the fact that it is lined almost entirely by stratified squamous epithelium, whereas the male urethra, with its stratified or pseudo-stratified columnar epithelium, beginning at the neck of the fossa navicularis and extending backwards as far as the utriculus masculinus in the prostatic urethra, offers an ideal site for penetration by the gonococcus. When the barrier formed by the stratified squamous epithelium of the fossa navicularis is absent, as in cases of hypospadias, infection is far more likely to occur. Harkness states that this deformity is present in 1 in 25 of patients suffering from urethritis, gonococcal or non-gonococcal, whereas Rennes (1831) and Bouisson (1861), who are cited by Nové-Josserand (1922), reported the incidence of hypospadias in the male population to be 1 in 300 . This has an important parallel in the female. The female urethra with its lining of stratified squamous epithelium does not present a good medium for penetration by gonococci deposited at the meatus. However, the para-urethral ducts lined by columnar epithelium, which open at the meatus, offer to the gonococcus an ideal situation away from the harmful effects of urine, and, theoretically, it would appear that infection of the urethra in the female is primarily an infection of the para-urethral ducts. The inactivity advocated in the male to prevent the spread of infection from the posterior urethra to the prostatic ducts is impossible to practise in their homologues in the female. Intercourse, the wearing of internal sanitary protection, and clinical examination involving massage of the urethra, all facilitate the spread of infection throughout the glands.

Spread to the few areas of columnar epithelium in the urethra may occur. However, as Harkness (1948) points out, the extreme rarity of subsequent stricture formation seems to indicate that very few areas of the urethra are involved.

The response of the tissues to the infecting organism may cause a blockage of the ducts of the glands by leucocytes and desquamated epithelial cells, which results in the formation of a closed focus of infection. Gonococci imprisoned in such a focus, but not reached by systemic treatment, in time lose their pathogenicity. The para-urethral glands in the female, however, are exposed to many forms of friction and it is suggested that re-opening of closed foci in the glands is a common result of this friction, and that gonococci which have escaped systemic treatment are so freed to re-infect other areas after treatment has ceased. 


\section{Clinical Manifestations}

Incidence of Infection.-Infection of the urethra, including the para-urethral ducts, occurs in the great majority of cases of gonorrhoea in the female (Menge, 1910; King and Mascall, 1935 ; Nicol, 1948).

The results obtained in the series of 106 cases reported in this paper show a striking difference in the distribution of infection as revealed by smear and culture tests (Table I).

\section{TABLE I}

POSITIVE FINDINGS IN SMEARS AND CULTURES

\begin{tabular}{|c|c|c|c|c|}
\hline \multirow{2}{*}{\multicolumn{3}{|c|}{ Site of Infection }} & \multicolumn{2}{|c|}{ Percentage Positive Results } \\
\hline & & & Smears & Cultures \\
\hline Urethra & . & .. & 29 & 65 \\
\hline Cervix .. & .. & .. & 42 & 67 \\
\hline No. of Cases & $\ldots$ & .. & 106 & 77 \\
\hline
\end{tabular}

The low proportion of positive urethral smears is probably due to the fact that very few patients showed signs of acute infection. Congestion of the urethra was reported in only fourteen cases, and pus was absent from the smear preparation in over 50 per cent.

The incidence of clinical signs relating to the para-urethral ducts has not been reported, but Durel, in a personal communication, estimates that approximately one in eight of all women who attend the Saint-Lazare Hospital, Paris, show evidence of para-urethral infection. In only one in eight or ten of these does he find gonococci, but treatment is given in every case because he states that he has frequently seen a gonococcal infection transmitted as a result of a para-urethritis which has been ignored.

The infrequency with which gonococci are isolated is probably explained by the fact that cultural methods of diagnosis are not a routine measure at the Saint-Lazare Hospital.

Clinical Signs.-The duration of the infection is not a measure of the clinical signs, many women having minimal signs at the onset of an infection, and only exhibiting minor clinical abnormalities when the infection has been present for some time.

Infection of the urethra may involve either paraurethral glands alone, or the para-urethral glands and urethra.

Considering the anatomy and histology of the region it would appear that infection of the urethra alone is a very rare occurrence. The clinical signs vary according to whether the infection is acute, subacute, or chronic.

(1) Acute.-As a result of acute infection of the paraurethral glands the entire mucosa of the urethra becomes reddened, oedematous, and congested. Oedema, although extending throughout the length of the urethra, is most marked at the lower end. The mucous membrane at the external urinary meatus becomes everted, and when the labiae urethrae are separated, presents an acutely congested area. The orifices of the paraurethral ducts appear as small yellowish spots surrounded by a collar of congested oedematous mucosa. Pressure over the glands results in the extrusion of pus. If the infection spreads to areas of columnar epithelium in the urethra, uniform oedema of the whole length of the urethra can be felt by the palpating finger, and the typical yellow discharge can be expressed on massage. Abscess formation may occur in the para-urethral glands and in the mucous glands in the floor of the urethra. This stage is accompanied by subjective symptoms (scalding micturition and frequency).

(2) Sub-acute.-This stage may result from a recession of the above signs, or may be present as such from the beginning of the infection. General congestion of the urethra disappears, oedema is localized either to the floor of the urethra at the meatus, or (more frequently) to the collar of mucosa surrounding the orifices of the para-urethral ducts. These openings appear as bright red spots without surrounding congestion, and on careful palpation a bead of discharge, varying from mucoid to frank pus, is expressed. There are no subjective symptoms at this stage.

(3) Chronic.-This stage requires very careful examination, and is the one most frequently present, and most commonly overlooked. Oedema and discharge may be present separately or together.

Oedema may be localized to the duct orifices, or may also involve the floor of the urethra to a limited extent. In cases in which oedema is a marked feature the duct orifices are easily located, because the labiae urethrae are everted, and the duct, if normally opening internal to the urethral orifice, appears to open at the orifice. If the normal opening of the duct is external, then a collar of oedema is seen on either side of the urethra. In both cases the duct opening is seen as a central dimple, no congestion being present. The positions of the ducts may be asymmetrical due to different degrees of oedema.

On inspection a bead of discharge may be seen lying at the duct orifices. This may be extraneous and should be wiped away with a swab and massage applied to the length of the ducts to express any mucoid or purulent discharge which may be lying within them.

These signs of chronic infection of the glands, with absence of inflammation, are rarely described, only two such references having been found in the literature : Ross (1949) speaks of a mammillated appearance of the ducts, or a turgidity of the floor of the urethra, as indicating the presence of chronic para-urethritis; Durel (1950a) mentions the condition in similar terms. 
As in the sub-acute stage, there are no subjective symptoms.

Para-Urethral Abscess.-One case of para-urethral abscess was observed. The patient complained of no symptoms referable to the abscess, but oedema of the right and left para-urethral duct orifices was noted on inspection of the urethra. The degree of oedema was approximately the same on both sides, but the right duct appeared to bulge forward in an uncommon manner, making the duct orifices asymmetrical in spite of the fact that they were similarly placed, and had equal degrees of oedema. Palpation of the right duct area through the anterior wall of the vagina revealed a small swelling approximately a quarter of an inch internal to the duct orifice. The swelling was spherical, one sixth of an inch in diameter, cystic, and painless on palpation. Pus was obtained on aspiration.

\section{Examination}

The recognition of minor clinical signs in the female urethra is not easy owing to the many variations in the form of the orifice which result from child-bearing. Such signs are the common indication of infection of the para-urethral glands, and since their recognition in a patient is an important factor in successful treatment, the importance of a meticulous examination of the urethra is evident.

(1) Inspection.-It is essential that inspection should precede palpation so that the extrusion of a small bead of discharge from a para-urethral duct will not occur before the duct orifices have been located. The following routine has been evolved in the examination of the patients reported in this paper.

The labia minora are held apart by the thumb and middle finger of the left hand, and the vestibule and introitus are wiped with a dry swab. The presence of a deficient perineum, particularly of a prolapse of the anterior vaginal wall, is noted as this is usually associated with some oedema of the urethral floor. The presence of generalized congestion of the labia minora and introitus, with thin frothy discharge from the latter suggesting trichomonas infestation, is noted as this leads to congestion and oedema of the urethra. The general form of the urethra is observed. If opening externally, the position of the two or multiple paraurethral ducts is noted.*

The floor of the urethra just internal to the meatus is next inspected. The thumb and middle finger of the

\footnotetext{
* Schüller (1883) found a third duct present occasionally. This opens at the external urethral orifice in the mid-line posteriorly. Known as Schüller's duct, it has been observed by the writer on two occasions.
}

left hand which hold apart the labia minora also support the meatus at the sides.

The index finger is then placed just above the urethra in the region of the clitoris and the right hand holding a dry swab is placed just below the meatus and gently everts the posterior lip.

Varying movements of the three fingers of the left hand in conjunction with the right gives a very good exposure of the urethra.

(2) Palpation.-Should the orifices of the paraurethral ducts be found to open external to the meatus, the three fingers of the left hand are kept in position as described above, and the index finger of the right hand is used for massage. It is important that massage should be limited, at first, to the lower half-inch of the urethra so that the discharge stripped from the length of the urethra does not hide beads expressed from the ducts. The massage should take place from within outwards, and should at first be directed centrally, and then on either side of the urethra.

The importance of this was demonstrated to the writer in one case. The patient attended the clinic as a contact, her husband being bacteriologically positive for gonorrhoea. Smear and culture examinations of the patient were negative, and no urethral pus was reported by the laboratory. The patient was, however, treated with 300,000 units of penicillin in oil-wax on epidemiological grounds, and told to report to the clinic again in one week. During this period the husband, who had become bacteriologically negative following treatment, was re-infected after intercourse with his wife. The wife was re-examined, the case being demonstrated by a nurse. Nothing abnormal was found on inspection, and massage of the urethra brought forth no discharge. Bearing in mind the possibility of infection of the para-urethral ducts in such a case, the writer applied massage lateral to the urethra on each side, and a bead of white discharge appeared at each of the duct orifices. Urethral smears on this occasion revealed no pus or gonococci, but gonococci were grown in the urethral culture.

If the ducts open internal to the meatus a better view is obtained if the thumb and middle finger of the left hand are moved a little posteriorly so that they are slightly behind the plane of the meatus. By exerting slight traction anteriorly with the index finger, and posteriorly with the thumb and middle finger, a good view of the floor of the urethra is obtained and the right hand is free for palpation and massage.

Massage should next be applied to the length of the urethra through the anterior vaginal wall, and the type of discharge obtained recorded. The distribution of oedema, and the presence of seedlike swellings in the posterior wall of the urethra should be noted.

Durel (1950a), describing his method of examining the para-urethral ducts, advises that an assistant, 
or the patient herself, should hold apart the labia minora. He steadies the urethra with the index finger of the left hand, and massages the length of urethra from before backwards and below upwards. This results in gaping of the meatus and protrusion of the duct orifices.

\section{Diagnosis}

(1) Clinical Examination.-It is essential that the examination should be undertaken by the clinician, and not by the nursing staff, however competent. Careful observation of the orifices of the ducts is necessary when massage of the urethra is being carried out, and masking of the orifices for a moment may result in a slight discharge coalescing with a descending urethral discharge so that its origin is missed. Examination is performed as already described.

(2) Bacteriological Tests.-These should be carried out when there is a generalized congestion of the pelvic organs, that is, immediately following a menstrual period.

(a) Examination of Stained Smears.-The difficulties of diagnosis by this method have been stressed by McLeod (1947) and by Cooper and others, (1950). They are greatest in chronic cases where the number of pus cells and gonococci are relatively few. As the majority of women who are eventually diagnosed as suffering from gonorrhoea come into this category, reliance upon this method would result in failure to establish the diagnosis in a large proportion of cases.

(b) Cultural Tests.--The superiority of cultural tests in the diagnosis of gonorrhoea in women has been frequently reported (McLeod, 1947; Lees, 1947 ; Nicol, 1948 ; Cooper and others, 1950). Nicol (1948) found that relapses yield a greater proportion of positive cultures than initial infections, and this was confirmed by Wilkinson (1949). In the series of 106 cases analysed in this paper, smear and culture tests were carried out in 77 cases. Positive cultures were obtained in 88 per cent. of the 77 cases, and positive smears in 36 per cent. Cultures were responsible for the diagnosis in 63 per cent. of the cases.

\section{Treatment}

The treatment of infected para-urethral glands has always proved most difficult unless the glands themselves are destroyed. This was stressed by Milton (1876), Skene (1880), and Luys (1912).

Systemic measures were reported soon after their introduction to be unsatisfactory in treating closed foci of infection. Marshall (1945), who advises cauterization of the length of the duct under general anaesthesia, says :

After seeing many cases of local abscess formation, and peri-urethral bartholinitis, I have the impression that penicillin, the drug employed, cannot replace surgery.

Ross (1949) says that treatment should be by ablation of the ducts with the electric cautery, or if the latter is not available, by injection of 125,000 units penicillin in $2 \mathrm{ml}$. sterile water into the mucous membrane of the floor of the urethra.

Durel (1950a) maintains that irrigation is practically without value, that local injection of penicillin into the mucous membrane is only occasionally effective, and that cauterization does not always lead to a cessation of the discharge. He advocates the use of diathermy by means of a special electrode which he has designed. He places one electrode into the urethra, and one into the duct, and opens the duct into the urethra. The wound heals from below, and the urine washes away the scab.

The writer has used two methods of treatment :

(1) Cauterization.-This is carried out under local anaesthesia with 2 per cent. procaine with adrenaline 1 in 1,000 . The adrenaline is not necessary for chronic cases, but better anaesthesia has been obtained with it when there is much hyperaemia. A dental syringe is used so that injection by the very fine needle is practically painless. The mucous membrane of the floor of the urethra is first infiltrated ; the needle is then withdrawn slightly and the direction changed, and the mucous membrane of the right lateral wall of the urethra is infiltrated according to the position of the duct. This is followed by the infiltration of the left lateral wall. The cautery is then passed down the affected ducts, and the floor of the urethra is cauterized when necessary. This procedure occupies only one or two minutes, and is usually painless. No discomfort is experienced afterwards.

The writer has noticed a recurrence of discharge in some cases, and in these re-cauterization or local injection of penicillin has been carried out. Such a recurrence is probably due to one or both of two factors :

(a) Bad Technique.-Recurrence was more often seen in the writer's early cases.

(b) Length of Duct.-It is possible that persistence of the discharge may have occurred in cases with ducts so long that the end had not been reached by the cautery.

It seems unlikely that in such cases the gonococci survive the rise in temperature due to the adjacent cautery, but secondary invaders, more resistant to changes in temperature, may well do so, and persistence of pus would break down the scar and prevent cicatrization as in sinus formation. The writer has always re-cauterized the area or tried the effect of the second type of treatment-local injection of aqueous penicillin.

(2) Local Penicillin.-Very consistent results have not been obtained with this method, and cauterization is now used as the method of choice. The reason may be that 
diffusion throughout the glands is difficult, and that some are not reached by the penicillin, or, alternatively, that where there is a mixed infection penicillinaseproducing bacteria render the penicillin ineffective (Garrod, 1944). The bacteria which one would expect to be secondary invaders in that region are those found in the rectum, and it has been shown that these do in fact inactivate penicillin (Chain and Florey, 1944).

For a persistent urethral discharge the writer injects aqueous penicillin into the mucous membrane of the length of the urethra with a long, fine needle. The fact that this has given better results than in paraurethral infections, indicates that diffusion is the difficulty in the treatment of the latter.

\section{Clinical Findings}

In this series of 106 cases of gonorrhoea in the female the incidence of clinical signs in the urethra has been correlated with the bacteriological results. This procedure has confirmed the importance of cultural tests in the diagnosis of gonorrhoea in the female.

The cases represent an unselected series, being all bacteriologically positive cases of gonorrhoea registered at the Liverpool Royal Infirmary between February, 1948, and May, 1950.

Specimens for cultural tests were taken whenever possible, the limiting factor being the closure of the laboratory for half of the duration of one of the clinics. Between January and May, 1950, Stuart's medium was available for preservation, and specimens for culture were then taken in all cases. Specimens for direct culture were transported on swabs in sterile test-tubes to the City Laboratory, a quarter of a mile distant, the maximum delay being one hour. In both cases the medium used for the culture was McLeod's chocolate agar. Cultures were reported positive when typical colonies were recognized and picked out by the oxidase test. Fermentation tests were not done except in the few instances in which Stuart's medium had been used for preservation of the specimens.

Smears were reported positive when Gramnegative intracellular diplococci were seen.

Incidence of Clinical Signs in the Para-Urethral Glands. - A detailed examination was carried out in 92 out of the series of 106 cases.* $^{*}$

Oedema.-In cases with oedema of the urethral orifice the para-urethral ducts are of necessity also involved, because of their anatomical situation. In such cases oedema of the urethra has been recorded.

* A detailed record of the clinical findings in the urethra is not available in fourteen of the 106 cases, owing to the writer's absence from the clinic during leave.
Congestion.-This was identified a clinical sign in the same manner.

Discharge.-This was recorded as occurring in the para-urethral ducts alone, when discharge was expressed from the ducts and none was obtained from the urethra, or as occurring in combination with a urethral discharge when both sites were separately seen to yield a discharge. In some cases in which the para-urethral ducts open internal to the urethral orifice, and in which a urethral discharge is present, the occurrence of a para-urethral discharge is masked. Any such cases which may have occurred in this series will have been recorded as cases of urethral discharge only. The results are analysed in Table II.

TABLE II

ANALYSIS OF CLINICAL SIGNS

\begin{tabular}{|c|c|c|c|c|c|c|}
\hline \multicolumn{3}{|c|}{ Clinical Signs } & \multicolumn{2}{|c|}{$\begin{array}{l}\text { In Para-urethral } \\
\text { Ducts }\end{array}$} & \multicolumn{2}{|c|}{ In Urethra } \\
\hline & & & No. & $\%$ & No. & $\%$ \\
\hline Oedema & . & . & 33 & 36 & 24 & 26 \\
\hline \multirow{3}{*}{ Discharge } & Ducts .. & .. & 11 & \multirow{2}{*}{; 23} & - & - \\
\hline & Ducts + & & 10 & & 10 & \multirow{2}{*}{31} \\
\hline & Urethra. . & . & $\div$ & - & 19 & \\
\hline \multicolumn{2}{|l|}{ Congestion } & .. & 4 & 4 & 10 & 11 \\
\hline \multicolumn{3}{|c|}{$\begin{array}{r}\text { Total Cases in which Signs } \\
\text { were seen } . . \\
.\end{array}$} & 43 & 47 & 50 & 54 \\
\hline
\end{tabular}

The figures in Table III show a tendency for clinical signs occurring in the para-urethral ducts to be of greater diagnostic significance than those occurring in the urethra.

TABLE III

CORRELATION OF CLINICAL SIGNS WITH BACTERIOLOGICAL RESULTS

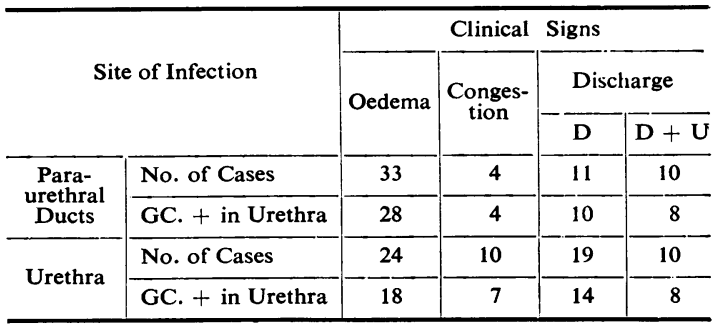

Clinical signs were found in the para-urethral ducts in the absence of all clinical signs in the urethra in 25 (27 per cent.) cases. In 22 of these 25 cases gonococci were found on bacteriological examination of the urethral specimen (Table IV).

The importance of cultural tests is again demonstrated by the fact that in only seven of these 25 
cases was pus reported, and in only six were gonococci seen in the urethral smear preparation.

\section{TABLE IV}

CORRELATION OF CLINICAL SIGNS IN THE PARAURETHRAL DUCTS AND BACTERIOLOGICAL RESULTS IN 25 CASES IN WHICH CLINICAL SIGNS IN THE URETHRA WERE ABSENT

\begin{tabular}{ll|c|c|c|c}
\hline Clinical Signs & $\ldots$ & $\begin{array}{c}\text { Oedema } \\
\text { only }\end{array}$ & $\begin{array}{c}\text { Discharge } \\
\text { only }\end{array}$ & $\begin{array}{c}\text { Oedema } \\
\text { and } \\
\text { Discharge }\end{array}$ & Total \\
\hline No. of Cases & $\ldots$ & 15 & 3 & 7 & 25 \\
GC. $+\quad$. & $\ldots$ & 13 & 3 & 6 & 22 \\
\hline
\end{tabular}

Case Histories.-Space does not permit the presentation of many case histories. The following small group of early cases briefly reported below represents the type of case which directed the writer's attention to the subject and resulted in the investigation. A detailed report of the urethra was not made, as the examination, judged by later standards, was perfunctory. Local treatment of the para-urethral ducts was not carried out until bacteriological relapse, or until pus was persistently reported in the urethral smear preparation. Cultural tests were not possible in all cases as preserving media were not then available.

Case 1.-(F.46/93). First attendance 1.2.46, aged 18 years, unmarried. No complaints, attended at request of consort who was under treatment for gonorrhoea. Examination revealed much oedema of the para-urethral ducts, some muco-pus in vagina. Smears urethral and cervical : gonococci present. Penicillin in aqueous solution, 150,000 units in divided dosage of 30,000 units 2-hrly, administered 7.2.46.

Patient defaulted, returned 22.7.47, now married, with husband under treatment for gonorrhoea, and child aged 5 mths., who received treatment for ophthalmia neonatorum shortly after birth. Smears negative for gonococci, few pus cells present in urethral smears. Re-treatment on epidemiological grounds : penicillin in oil-wax 300,000 units.

21.8.47 : no gonoccoci, pus ++ in urethral smears.

1.9.47: gonowocci + , pus ++ in urethral, no gonococci present in cervical. Re-treatment : penicillin in oil-wax 300,000 units intramuscularly, sodium penicillin in aqueous solution 250,000 units injected into mucous membrane of urethra and para-urethral ducts.

Post-menstrual tests 11.11.47 and 16.1.48: smears negative for gonococci and pus in urethral, cultures negative.

Case 2.-(F.46/157). First attendance 6.11.45, aged 17 yrs, unmarried. No complaints, wished to exclude possibility of venereal infection after exposure to one consort. Nothing abnormal found on examination. Smears : no gonococci, pus + in urethral.

Post-menstrual smears 19.2.46: no gonococci, pus ++ in urethral. Owing to absence of cultural facilities treatment given 28.3.46 in view of persistent urethral pus : penicillin in aqueous solution 150,000 units in divided dosage of 30,000 units 2-hrly.

Post-menstrual smears 7.5.46: no gonococci, pus : few in urethral.

Post-menstrual smears 17.6.46: gonococci + , pus
++ in urethral, cervical negative. Treatment : sulphathiazole $1 \mathrm{~g}$. 4-hrly for 5 days $(20 \mathrm{~g}$.).

Post-menstrual smears 13.8.46: no gonococci, pus + in urethral. Examination revealed hypertrophy and oedema of right para-urethral duct. Ducts cauterized 10.9.46.

Post-menstrual smears 1.4 .47 and 1.7.47 : no gonococci, no pus in urethral smear.

Case 3.-(F.47/53). First attendance 21.1.47, aged 27 yrs, unmarried. Attended at request of consort who was under treatment for gonorrhoea. Complained of discharge. Smears : no gonococci, pus : few in urethral. Treatment on epidemiological grounds : penicillin in ethyloleate 250,000 units.

30.1.47 : smears no gonococci, pus: few in urethral.

Examination 18.2.47 prior to post-menstrual tests: much congestion of para-urethral ducts, bead of discharge expressed from ducts on palpation. Ducts cauterized on clinical grounds. Result of smears : gonococci + , pus ++ in urethral and cervical. Retreatment on next attendance 25.2.47: penicillin in oil-wax 200,000 units.

Post-menstrual smears and cultures 1.4.47, 24.4.47, 27.5.47 and 22.7.47 : no gonococci, pus few to negative in urethral.

Case 4.-(F.47/87.) First attendance 4.2.47, aged 20 yrs, married 2 yrs, one child $1 \frac{1}{2}$ yrs old. Attended at request of husband who was under treatment for gonorrhoea. Complained of discharge of 9 days' duration. Last marital coitus 26.1.47, extra-marital coitus denied. Examination: moist vulva, discharge expressed from urethra, and much discharge present in vagina. Cervix eroded. Treatment on epidemiological grounds: penicillin in oil-wax 300,000 units. Smears : gonococci $t$, pus ++ in urethral and cervical.

Post-menstrual smears 14.2.47 : no gonococci, pus : few in urethral.

14.3.47: gonococci + , pus ++ in urethral and cervical. Re-treatment : penicillin in oil-wax 300,000 units at 10 a.m. and 3 p.m.

Post-menstrual smears 18.4.47: no gonococci, pus ++ in urethral. In view of persistent pus in urethral smear preparation cauterization of para-urethral ducts was carried out.

In five post-menstrual tests no gonococci were reported and urethral pus varied between "few" and negative.

Case 5.-(F.46/271). First attendance 2.1.46, aged 20 yrs, unmarried. History of exposure to two consorts, last coitus 5 months previously. Complained of discharge of 10 weeks' duration. Examination : congestion of urethra and copious muco-purulent discharge in vagina. Cervix congested. Smears : gonococci + in cervical ; no gonococci, pus + in urethral. Treatment : sodium penicillin in aqueous solution 150,000 units in divided dosage of 30,000 units 2-hrly.

Post-menstrual tests 10.5.46 : smears : gonococci + , pus + urethral and cervical; cultures positive. Re-treatment 28.5.46: penicillin in ethyloleate 250,000 units. Examination of urethra showed congestion and oedema of para-urethral ducts. Cauterization carried out.

Post-menstrual smears 2.7.46, 20.8.46, and 5.10.46: no gonococci, but urethral pus persistently reported. Oedema still present and re-cauterization carried out. Three post-menstrual tests finally showed disappearance of urethral pus. 


\section{Summary and Conclusions}

Whereas, in the early days of penicillin treatment of gonorrhoea, cure rates of up to 100 per cent. were claimed after a single course of penicillin, recent reports take a more cautious view, and suggest that the failure rate may be higher than was at first believed.

The isolation of the gonococcus from the female secretions is a difficult problem due to the inaccessibility of the infecting organism, and to the presence of secondary invaders. The availability of good bacteriological facilities is essential for the diagnosis of gonorrhoea in the female, as without an efficient culture service a large proportion of initial infections, and an even larger proportion of relapses, will be undetected. In the 77 cases tabulated, cultural methods were responsible for the diagnosis in 64 per cent. of cases.

The chronic character of a gonococcal infection in the female is demonstrated by the fact that no pus was reported in the urethral smear preparation in 56 ( 72 per cent.) of the 77 cases in which morphological examination and cultural tests were possible, although gonococci were isolated by cultural methods in 37 ( 64 per cent.) of these cases.

In the majority of cases in which failure to respond to a single course of penicillin treatment has occurred, no cause has been found for the failure, and re-treatment with penicillin has been carried out on empirical grounds. That gonococci lying within a closed focus of infection are unaffected by systemic penicillin has been stressed by many writers, and it is possible that relapse is due to the conversion of these closed foci into intermittently draining foci with the consequent release of gonococci.

The anatomical situation and histological formation of the para-urethral glands make them a potential primary focus of infection in all cases of gonorrhoea in the female. The frequent occurrence of signs of infection in the glands has been confirmed clinically in the 92 cases reported, 43 (47 per cent.) showing evidence of infection. In 25 ( 27 per cent.) cases, signs relating to the para-urethral ducts occurred in the absence of clinical signs in the urethra, and in 22 (88 per cent.) of these 25 cases gonococci were found. Spread of infection throughout the glands is facilitated by the many forms of friction to which the glands are exposed.
The resistance to treatment of infection of the glands has long been recognized; it would appear to result from the formation of small closed foci of infection due to blockage of the ducts by debris, and the conversion of these closed foci into intermittently draining foci by the friction to which they are subjected. It is, therefore, suggested that infection of the para-urethral glands is the cause of the persistence of gonococcal infection in many cases of relapse, and that in cases which show signs of chronic infection of the glands at the time of diagnosis, destruction of the glands, combined with systemic treatment is the quickest, and in some. cases the only, method of effecting a cure.

\section{REFERENCES}

Astruc, J. (1761). "Traité des maladies des femmes", 1st ed., vol. 3, p. 7. Cavelier, Paris (Cited by Durel, 1950a).

Bouisson, E. F. (1861). "Tribut à la chirugie (1858-61)." Baillière, Paris (Cited by Nové-Josserand, 1922).

Bigger, J. W. (1944). Lancet, 2, 497.

Chain, E., and Florey, H. W. (1944). Brit. med. Bull., 2, 5.

Cooper, K. E., Mayr-Harting, A., and McLachlan, A. E. W. (1950). British Journal of Venereal Diseases, 26, 16.

Durel, P. (1950a). “La blennorragie”, pp. 248 ; 268-9 ; 528. Masson, Paris.

- (1950b). Personal communication.

Garrod, L. P. (1944). Brit. med. J., 1, 528.

Gray, H. (1935). "Anatomy ; descriptive and applied ", 26th ed., pp. 192 ; $195 ; 1362$, ed. T. B. Johnston. Longmans Green, London.

Harkness, A. H. (1948). British Journal of Venereal Diseases, 24, 137.

King, A. J., Curtis, F. R., and Nicol, C. S. (1950). Lancet, 1, 701. $\longrightarrow$, and Mascall, W. N. (1935). Ibid., 1, 1492.

Lees, R. (1946). Brit. med. J., 1, 605.

-(1947). British Journal of Venereal Diseases, 23, 58. (Report of Discussion.)

Luys, G. (1912). "Traité de la blennorragie." Doin, Paris. "A Text-book of Gonorrhea", trans. and ed. A. Foerster, 3rd. ed., pp. 262 ; 266. Baillière, Tindall and Cox, London. McLeod, J. W. (1947). British Journal of Venereal Diseases, 23, 53. Marshall, J. (1945). Presse méd., 53, 534.

Mascall, W. N. (1946). Lancet, 2, 712.

Menge, C., and Opitz, E. (1913). "Handbuch der Frauenheilkunde," Bergmann, Weisbaden (Cited by Shaw, 138 ).

Milton, J. L. (1876). " On the Pathology and Treatment of Gonorrhoea ", 4th ed., p. 20. Hardwicke and Bogue, London.

Moore, J. E. (1949). British Journal of Venereal Diseases, 25, 169.

Nicol, C. S. (1948). Ibid., 24, 26.

Nové-Josserand, G. (1922). In " Encyclopédie française d'urologie ", ed. A. Pousson, and E. Desnos, vol. 5, p. 859. Doin, Paris.

Rennes, -. (1831). Arch. gén. Med., 26, 360, and 27, 17 (Cited by Nové-Josserand, 1922).

Ross, A. O. F. (1949). Practitioner, 162, 383.

Schüller, (1883). “Festschrift f. Bernard Schultze”, vol. 4, p. 16. Berlin.

Shaw, W. (1938). “Textbook of Gynaecology", 2nd ed., p. 149. Churchill, London.

Skene, A. J. C. (1880). Amer. J. Obstet. Dis. Wom., 13, 265.

Warner, B. (1944). Med. J. Aust., 2, 494.

Wilkinson, A. E. (1949). British Journal of Venereal Diseases, 25, 9. 